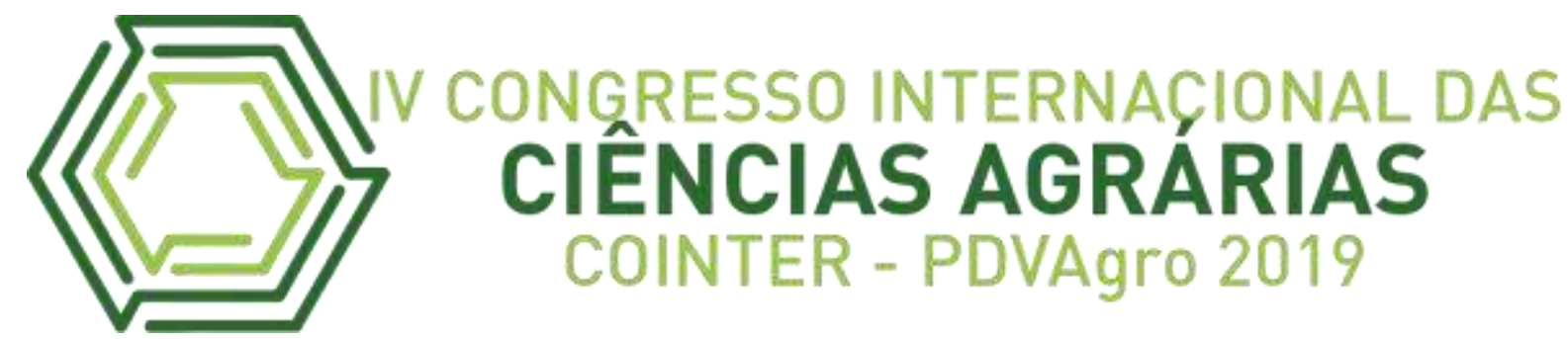

\title{
ATRIBUTOS FíSICOS DO SOLO SOB SISTEMA DE CULTIVO DA UVA EM TOPOSEQUENCIA E MATA NATIVA
}

\section{ATRIBUTOS FÍSICOS DEL SUELO BAJO EL SISTEMA DE UVA TOPOSEQUENCIA Y EL BOSQUE NATIVO}

\section{SOIL PHYSICAL ATTRIBUTES UNDER TOPOSEQUENCIA GRAPE SYSTEM AND NATIVE FOREST}

Apresentação: Comunicação Oral

José Denilson da Silva ${ }^{1}$; Luis Felipe Silva Menezes²; Sandro Augusto Bezerra ${ }^{3}$

DOI: $\underline{\text { https://doi.org/10.31692/2526-7701.IVCOINTERPDVAgro.2019.0029 }}$

\section{Resumo}

Os atributos físicos do solo permitem monitorar as áreas que sofrem como impacto da agricultura. A partir deste conhecimento podemos determinar as formas de manejo para cada solo dependendo de sua especificidade, pois eles auxiliam na caracterização do tipo de solo e maneira de ser trabalhado. Este trabalho teve como objetivo caracterizar e descrever a qualidade física de um ARGISSOLO VERMELHO AMARELO sob diferentes sistemas de uso e manejo de UVA e mata nativa, avaliando sua densidade do solo e umidade gravimétrica. A pesquisa foi desenvolvida na propriedade do Sr. Pedro localizada no município de São Vicente Férrer PE, localizado na mesorregião do Agreste Pernambucano do Médio Capibaribe, com altitude de $570 \mathrm{~m}$, declividade média da área de $15 \%$. Foi utilizado o delineamento experimental de parcelas subdivididas, onde os tratamentos principais foram formas de uso do solo sob cultivo da videira em topossequência, e mata nativa e os tratamentos secundários foram quatro camadas do solo $(0,0-0,1 \mathrm{~m} ; 0,1-0,2 \mathrm{~m} ; 0,2-0,3 \mathrm{~m}$; e 0,3-0,4 m), sendo utilizadas cinco repetições. Os tratamentos foram: UCT: Uva e cobertura viva do solo em Topo; UCE: Uva e cobertura viva do solo em Encosta; UCV: Uva e cobertura viva do solo em Várzea; MN: Mata Nativa. Foi possível observar que a área de Mata Nativa apresentou os melhores resultados tanto de Densidade do solo nas camadas estudadas quando de umidade gravimétrica, permitindo inferir que a alteração da mata nativa em área de cultivo de Uva, seja em qualquer declividade, promove degradação da qualidade física do solo, visto que não há nas áreas de cultivo o manejo correto, tornando esta condição degradadora de solos.

1Bacharelado em Agronomia, IFPE-Campus Vitoria de Santo Antão, denisonsila@gmail.com 2 Bacharelado em Agronomia, IFPE-Campus Vitoria de Santo Antão, luisfelipesmenezes@gmail.com 3 Doutor, IFPE-Campus Vitória de Santo Antão, sandro.augusto@vitoria.ifpe.edu.br 
Palavras-Chave: Densidade do solo, umidade gravimétrica, cultivo da videira

\title{
Resumen
}

Los atributos físicos del suelo nos permiten monitorear las áreas afectadas por la agricultura. A partir de este conocimiento, podemos determinar las formas de manejo de cada suelo en función de su especificidad, ya que ayudan a caracterizar el tipo de suelo y la forma de trabajar. Este trabajo tuvo como objetivo caracterizar y describir la calidad física de un ARGISSOL ROJO AMARILLO bajo diferentes sistemas de uso y manejo de UVA y bosques nativos, evaluando su densidad del suelo y humedad gravimétrica. La investigación se llevó a cabo en la propiedad del Sr. Pedro ubicada en São Vicente Férrer - PE, ubicada en la mesorregión de Agreste Pernambucano del Medio Capibaribe, con una altitud de $570 \mathrm{~m}$, pendiente promedio del área del $15 \%$. Se usó el diseño experimental de parcelas subdivididas, donde los tratamientos principales fueron formas de uso de la tierra bajo cultivo de vid de secuencia posterior, y el bosque nativo y los tratamientos secundarios fueron cuatro capas de suelo $(0.0-0.1 \mathrm{~m} ; 0,1-0.2$ $\mathrm{m}, 0.2-0.3 \mathrm{~m}$, y $0.3-0.4 \mathrm{~m}$ ), usando cinco repeticiones. Los tratamientos fueron: UCT: uva y cobertura del suelo vivo en Topo; ECU: Uva y cobertura del suelo en Encosta; UCV: Uva y cobertura vegetal viva en Várzea; MN: bosque nativo. Se pudo observar que el área de bosque nativo presentó los mejores resultados de densidad del suelo en las capas estudiadas y la humedad gravimétrica, lo que permitió inferir que la alteración del bosque nativo en el área de cultivo de uva, en cualquier pendiente, promueve la degradación de la calidad. física del suelo, ya que no existe un manejo adecuado en las áreas cultivadas, lo que hace que este suelo se deteriore.

Palabras Clave: Densidad del suelo, humedad gravimétrica, cultivo de vid.

\begin{abstract}
The physical attributes of the soil allow us to monitor the areas that are impacted by agriculture. From this knowledge we can determine the management forms for each soil depending on its specificity, as they help in characterizing the soil type and way of working. This work aimed to characterize and describe the physical quality of a YELLOW RED ARGISSOL under different UVA and native forest use and management systems, evaluating its soil density and gravimetric humidity. The research was carried out in the property of Mr. Pedro located in São Vicente Férrer - PE, located in the mesoregion of Agreste Pernambucano of the Middle Capibaribe, with altitude of $570 \mathrm{~m}$, average slope of the area of $15 \%$. The experimental design of subdivided plots was used, where the main treatments were forms of land use under topossequence vine cultivation, and native forest and the secondary treatments were four soil layers $(0.0-0.1 \mathrm{~m} ; 0$, 1-0.2 m, 0.2-0.3 m, and 0.3-0.4 m), using five repetitions. The treatments were: UCT: Grape and living ground cover in Topo; ECU: Grape and ground cover in Encosta; UCV: Grape and live ground cover in Várzea; MN: Native Forest. It was possible to observe that the native forest area presented the best results of soil density in the studied layers and gravimetric humidity, allowing to infer that the alteration of native forest in grape cultivation area, in any slope, promotes quality degradation. soil physics, since there is no proper management in the cultivated areas, making this soil degrading condition
\end{abstract}

Keywords: Soil density, gravimetric humidity, vine cultivation 


\section{Introdução}

As diferentes feições do relevo, intensidade e duração dos processos pedológicos e as características do material de origem determinam o tipo e a distribuição do solo nas paisagens (Wysocki et al. 2005), segundo uma lógica relacionada aos processos geomorfogenéticos e pedogenéticos. A paisagem é um condicionador do ambiente e a sua configuração tem relação íntima com o relevo, para formação de condições específicas, em diferentes regiões (Phillips et al. 2001). As variações nos atributos do solo são devidas a vários fatores, dentre eles a posição do solo na paisagem, drenagem do terreno, processos de erosão e deposição e desenvolvimento da vegetação (Cantón et al. 2003).

De acordo com REINERT e REICHERT, (2006) a física de solos estuda e define, qualitativa e quantitativamente, as propriedades físicas, bem como sua medição, predição e controle, com o objetivo principal de entender os mecanismos que governam a funcionalidade dos solos e seu papel na biosfera.

A definição de um solo fisicamente ideal é difícil devido ao tipo e natureza das variações físicas dos solos que ocorrem ao longo da profundidade do solo, na superfície da paisagem e ao longo do tempo. (REINERT e REICHERT, 2006)

As propriedades físicas do solo indicam sua qualidade física, que por sua vez estão diretamente relacionadas à capacidade de infiltração, retenção e disponibilidade de água às plantas, além capacitar as trocas gasosas da atmosfera com as raízes e permitir o crescimento vegetal sem impedimentos (FERREIRA et al., 2010). A obtenção das propriedades físicas do solo é a principal forma de identificar a compactação dos solos. Entre as inúmeras propriedades pode-se citar: a resistência do solo à penetração; a densidade do solo e a umidade gravimétrica do solo.

A Uva Isabel é uma cultivar de uva tinta, muito rustica e altamente fértil, proporcionando colheitas abundantes. É consumida como uvas de mesa, vinhos, sucos ou elaboração de vinagres. O município de São Vicente Férrer, no agreste de Pernambuco, se destaca por possuir $90 \%$ da área destinada a viticultura no agreste, plantada com videira Isabel (Embrapa, 2009). O cultivo é desenvolvido em pequenas propriedades de 0,5 ha a 12 ha, elemento que, segundo Flores et al. (2005), valoriza a produção e a qualidade da uva. 
Como em qualquer atividade agrícola o bom desenvolvimento da cultura é de extrema importância para o produtor. E para este bom êxito diversas práticas de manejo devem ser incorporadas ao sistema produtivo. O estudo de atributos físicos de um solo é uma dessas práticas eficazes para trabalhar com atividades agrícolas. Que além da produtividade, a sustentabilidade é um grande desafio dos setores agrícolas para a produção de alimentos.

Neste contexto, os conhecimentos dos atributos físicos do solo permitem monitorar as áreas que sofrem como impacto da agricultura. A partir deste conhecimento podemos determinar as formas de manejo para cada solo dependendo de sua especificidade, pois eles auxiliam na caracterização do tipo de solo e maneira de ser trabalhado.

\section{Fundamentação Teórica}

As primeiras variedades de uvas foram introduzidas no Brasil pelos portugueses. Eram uvas finas (Vitis vinifera), cultivadas na Europa e selecionadas com base em informações e experiência pessoal dos vitivinicultultores europeus. A viticultura brasileira, porém, somente se consolidou em meados do século XIX, com a introdução da cultivar de uva americana Isabel (Vitis labrusca) pelos imigrantes italianos, culminando na rápida substituição dos vinhedos de uvas européias. (EMBRAPA, 2010).

A vitivinicultura brasileira é importante para o Rio Grande do Sul, na serra gaúcha, onde quase a totalidade da produção se destina à agroindústria do suco e do vinho e essencialmente produzida por pequenos agricultores de agricultura familiar. Na produção de uvas de mesa, a cultura se destaca no Vale do São Francisco (Pernambuco e Bahia) e em São Paulo, gerando renda para milhares de famílias. Nos últimos anos, com a implementação das Indicações Geográficas no Brasil, a viticultura tem contribuído fortemente para o desenvolvimento dos territórios envolvidos, promovendo a agregação de valor aos produtos e a valorização de seus respectivos fatores naturais e culturais (MELLO, 2014).

Os solos, quando submetidos a determinados sistemas de cultivo, tendem a um novo estado de equilíbrio, refletido em diferentes manifestações de seus atributos, as quais podem ser desfavoráveis à conservação da capacidade produtiva destes solos.(CARDOSO,2014). Os efeitos diferenciados sobre os atributos do solo, devido ao tipo de preparo, característico de cada sistema de cultivo, são dependentes da intensidade de revolvimento, do trânsito de máquinas, do tipo de equipamento utilizado, do manejo dos resíduos vegetais e das condições de umidade do solo no momento do preparo. 
À medida que o solo sofre intervenções no uso, ocorrem modificações nos seus atributos físicos como o aumento da densidade do solo, diminuição da porosidade total, distribuição do diâmetro dos poros, alteração na agregação e no teor de matéria orgânica. Estudos mais específicos com atributos físicos do solo evidenciam que esses variam de um local para outro, apresentando continuidade ou dependência espacial, dependendo do manejo adotado e material de origem dos solos (Silva et al., 2004; Souza et al., 2006; Amaro Filho et al., 2007; Camargo et al., 2008; Botega et al., 2011).

Topossequência é o nome que se dá a sequência de solos que pode ser observada ao longo de uma encosta. Ao se analisar, por exemplo, toda a seção transversal de uma encosta de um vale fluvial, do topo em direção à várzea, é possível observar, conforme a posição topográfica, uma série de variações condicionadas pela modificação dos fatores: disponibilidade de água, microclima, biota, predominância de processos de sedimentação, transporte ou erosão, etc. (TOPOSSEQUÊNCIA, 2017) O município de São Vicente Férrer fica localizado no Planalto da Borborema.

A viticultura da região é caracterizada por regiões de montanhas, sendo uma agricultura de grandes desafios devidos as altas declividades (Embrapa,2009). O estudo do solo em topossequência permite uma visão global e integrada dos vários componentes da paisagem. As topossequência têm sido utilizadas para compreender a pedogênese e o comportamento atual dos solos, sobretudo por estabelecer relações entre atributos do solo e relevo. Permitem elucidar as dinâmicas interna e externa do solo, a partir das suas variações verticais e laterais nas vertentes da bacia hidrográfica (Alves\& Ribeiro, 1995).

\section{Metodologia}

A pesquisa foi desenvolvida em uma propriedade do Sr. Pedro localizada em São Vicente Férrer é um município brasileiro do Estado de Pernambuco, localizado na mesorregião do Agreste Pernambucano do Médio Capibaribe ( $7^{\circ} 35^{\prime} 27^{\prime \prime}$ S, 35 $29^{\prime} 27^{\prime \prime} \mathrm{W}$ ), localizado no agreste de Pernambuco, com altitude de 570m, declividade média da área de $15 \%$. O clima é classificado como As', quente e úmido com chuvas de outono inverno (Beltrão \& Macedo, 1994). A precipitação média anual é de $1.103 \mathrm{~mm}$, sendo a temperatura média anual de $24^{\circ} \mathrm{C}$. A vegetação nativa é típica do agreste: Florestas Subcaducifólica e Caducifólia (SÃO 
VICENTE FERRER, 2017). As amostras foram obtidas no período de maio a Junho e armazenadas no Laboratório de Física do Solo do Instituto Federal de Pernambuco Campus Vitória de Santo Antão. O solo é classificado como sendo ARGISSOLO VERMELHOAMARELO.

Foi utilizado o delineamento experimental de parcelas subdivididas, onde os tratamentos principais foram formas de uso do solo sob cultivo da videira em topossequência, e mata nativa e os tratamentos secundários foram quatro camadas do solo $(0,0-0,1 \mathrm{~m} ; 0,1-0,2 \mathrm{~m} ; 0,2-0,3 \mathrm{~m}$; e 0,3-0,4 m), sendo utilizadas cinco repetições. Os tratamentos foram:

- UCT: Uva e cobertura viva do solo em Topo

- UCE: Uva e cobertura viva do solo em Encosta

- UCV: Uva e cobertura viva do solo em Várzea

- MN: Mata Nativa.

As amostras utilizadas para a obtenção da densidade do solo e umidade gravimétrica foram retiradas do mesmo ponto. A densidade do solo foi realizada de acordo a metodologia de Kopeck, onde utiliza um anel de metal com bordas cortantes com volume conhecido (Embrapa,1997). Os anéis foram cravados no solo cada um em suas respectivas camadas $(0,0$ 0,1 m; 0,1-0,2 m; 0,2-0,3 m; e 0,3-0,4 m) tendo o excesso retirado com o auxílio de um canivete. Sucessivamente os anéis foram envolvidos com um filme plástico e papel alumínio e guardados até a chegada ao laboratório para ser conservados a umidade do solo.

No laboratório foram pesadas as amostras, para obtenção do peso úmido do solo para os cálculos da umidade gravimétrica e levadas para estufa de $105^{\circ} \mathrm{C}$ por 24 horas, posteriormente pesados novamente para obtenção do peso seco das amostras. Baseado no peso seco da amostra e o volume do anel foi calculada a densidade do solo (Equação 1) e a partir do peso do solo úmido e seco calculada a umidade gravimétrica do solo (Equação 2).

$$
D s=\frac{M s}{V}
$$

Equação 1

Sendo,

Ds: Densidade do solo, $\mathrm{Kg} \mathrm{dm}^{-3}$;

Ms: Massa do solo seco, $\mathrm{Kg}$;

$\mathrm{V}$ : volume do anel volumétrico, $\mathrm{cm}^{3}$.

$$
U g=\frac{M u-M s}{M s}
$$


Sendo,

Ug: Umidade gravimétrica, $\mathrm{Kg} \mathrm{Kg}^{-1}$;

$\mathrm{Mu}$ : Massa do solo úmido, $\mathrm{Kg}$;

Ms: Massa do solo seco em estufa, Kg.

Os efeitos do cultivo da videira nos atributos físicos do solo em relação à aos demais tratamentos foram feitas com auxílio do software estatístico SISVAR, da Universidade Federal de Lavras (UFLA). O teste utilizado para comparação de médias foi o teste de Tukey ao nível de 5\% de probabilidade para a comparação das médias dos atributos dos solos. Ressalta-se que os resultados das análises físicas do solo não levaram em consideração a variação em profundidade nos tratamentos, mas entre os tratamentos em cada camada de solo avaliada. Todas as análises estatísticas foram realizadas com o programa estatístico SISVAR 5.1 (FERREIRA, 2007).

\section{Resultados e Discussão}

Na tabela 1 foi possível observar que os tratamentos UCT, UCE e UCV, não diferiram estatisticamente entre si, porem os maiores valores de densidade do solo foram encontrados no tratamento UCE com médias entre 1,38 a $1,43 \mathrm{~kg} \mathrm{~m}^{-3}$, e ainda em relação a esses tratamentos o menor valor de Densidade do solo foi encontrado na área UCT na camada de 0-10 m. Estes resultados são semelhantes aos obtidos por Bertol et al. (2004), pois os autores não observaram variação nas propriedades físicas do solo pelo uso de diferentes sistemas de cultivo, compreendido como rotação e sucessão com culturas de cobertura em somente um ciclo de produção, concluindo que seria provável a necessidade de realizar experimentos por período de tempo mais longo para poder verificar os resultados da ação das plantas sobre as propriedades físicas do solo.

Tabela 1. Médias de densidade do solo em diferentes sistemas de manejo nas quatro camadas avaliadas.

\begin{tabular}{lcccc}
\hline \multirow{2}{*}{ Manejo } & \multicolumn{3}{c}{ Camadas(m) } \\
\cline { 2 - 5 } & $0-0,1 \mathrm{~m}$ & $0,1-0,2 \mathrm{~m}$ & $0,2-0,3 \mathrm{~m}$ & $0,3-0,4 \mathrm{~m}$ \\
\hline $\mathrm{UCT}$ & $1,22 \mathrm{a}$ & $1,37 \mathrm{a}$ & $1,36 \mathrm{ab}$ & $1,36 \mathrm{ab}$ \\
$\mathrm{UCE}$ & $1,38 \mathrm{a}$ & $1,42 \mathrm{a}$ & $1,41 \mathrm{a}$ & $1,43 \mathrm{ab}$ \\
$\mathrm{UCV}$ & $1,28 \mathrm{a}$ & $1,31 \mathrm{ab}$ & $1,39 \mathrm{a}$ & $1,46 \mathrm{a}$ \\
$\mathrm{MN}$ & $0,97 \mathrm{~b}$ & $1,14 \mathrm{~b}$ & $1,14 \mathrm{~b}$ & $1,32 \mathrm{~b}$ \\
\hline $\mathrm{cv} \%$ & 9,72 & 7,79 & 10,03 & 5,77 \\
\hline
\end{tabular}


*médias seguidas pela mesma letras na coluna não diferem estatisticamente entre si, pelo teste de Tukey ao nível de 5\% de probabilidade. Sendo UCT: Uva com cobertura viva do solo em topo; UCE: Uva com cobertura viva do solo em encosta; UCV: Uva com cobertura viva do solo em Várzea e MN: Mata Nativa.

As médias de Densidade do solo da área do tratamento MN diferiram estatisticamente dos demais tratamentos, por serem as mais baixas, aumentando ao longo da profundidade. O que foi observado também no trabalho de Custodio et al (2015) em um Latossolo amarelo que avaliou diferentes manejos de pastagens e mata nativa.

A mata diferiu estatisticamente dos demais tratamentos com umas baixas densidades de solo em todas as camadas avaliadas. Tais resultados comprovam o efeito da manutenção de material orgânico oriundo de restos animais e vegetais oriundos de vegetação nativa não alterada contribuindo para o aumento da matéria orgânica e consequentemente equilíbrio na estrutura do solo nas camadas avaliadas.

Em todos os tratamentos a camada de $0,3-0,4 \mathrm{~m}$ foram as que apresentara as maiores densidades, havendo diferença entre os tratamentos de Topo e Encosta com a área de Várzea e MN com os demais tratamentos. Segundo Kiehl (1979), este comportamento pode estar relacionado ao peso das camadas adjacentes causando assim maior compactação em sub superfície.

Na figura 1, é possível observar que o tratamento que apresentou as maiores médias de densidade do solo, nas três camadas iniciais do solo, foi o UCE, exceto na camada de $0,3-0,4 \mathrm{~m}$ mas que não diferiu estatisticamente dos demais tratamentos da topossequência. Isso pode estar relacionado a condição física do solo em áreas de encosta, onde não é possível a concentração de permanente de material orgânico no solo, devido a declividade acentuada na área (15\%). O que foi observado, também, pela falta de práticas de conservação do solo que reduzisse o escoamento de água dentro da encosta. 
Figura 1- Valores médios de Densidade do solo em diferentes sistemas de manejo

Sendo UCT - Uva com cobertura viva do solo em Topo; UCE - Uva com cobertura viva do solo em encosta; UCV - Uva com cobertura em Várzea e MN - Mata nativa.

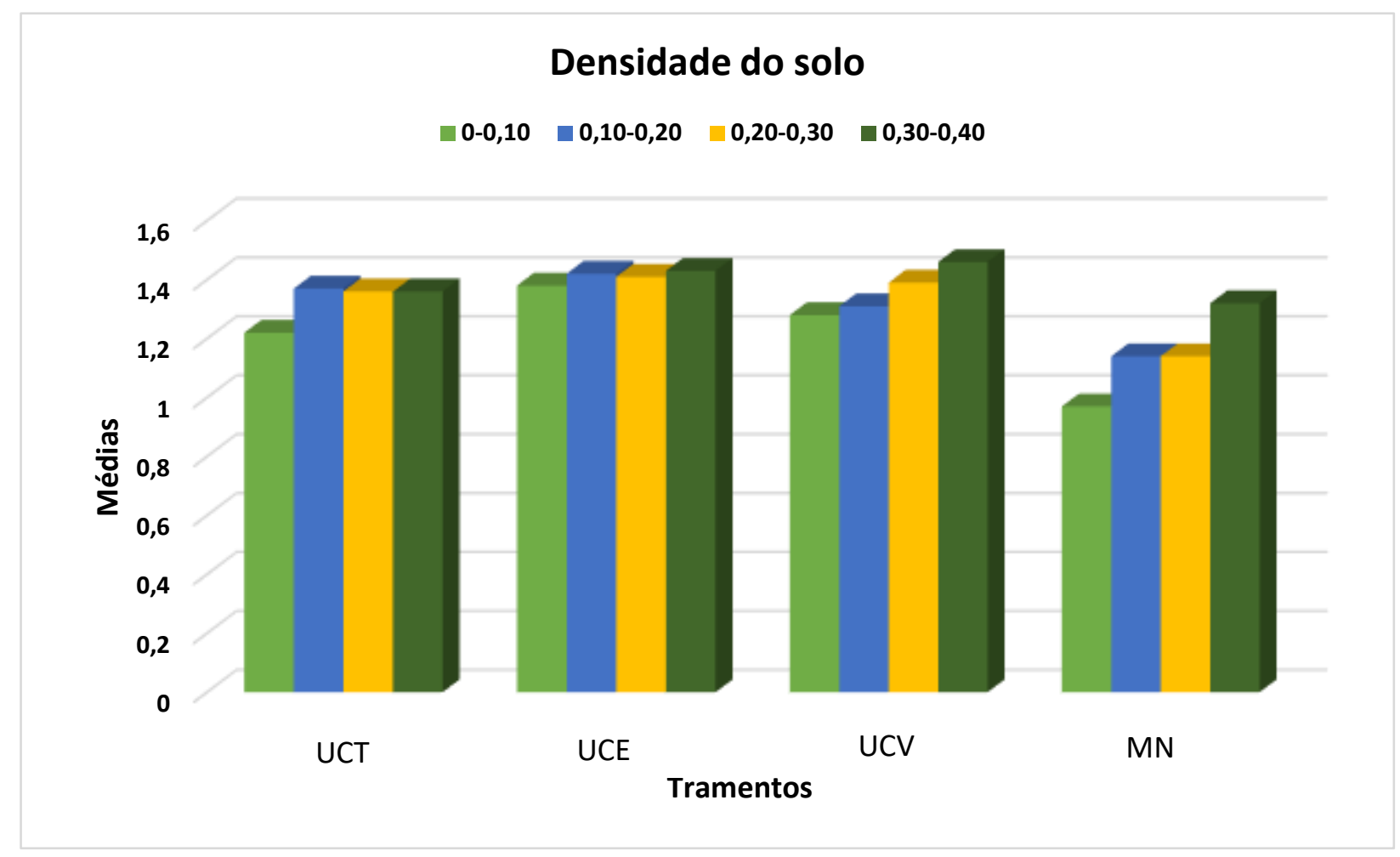

Os menores valores de Densidade do Solo (Tabela 1 e Figura 1) foram encontrados nas camadas de 0-10m, que pode estar relacionado ao acumulo de material orgânico, já que os tratamentos estavam cobertos com vegetação rasteira, menores valores de DS em camadas superficiais foram encontrados por Prevedelho et al. (2007) em estudo de um Argissolo Vermelho amarelo com cultivo de eucalipto, e atribuíram também a maior deposição de MO na superfície.

Tabela 2. Médias de umidade gravimétrica em diferentes sistemas de manejo nas quatro camadas avaliadas.

\begin{tabular}{lllcc}
\hline Manejo & \multicolumn{3}{c}{ Camadas(m) } \\
\cline { 2 - 5 } & $0-0,10$ & $0,10-0,20$ & $0,20-0,30$ & $0,30-0,40$ \\
\hline UCT & $0,12 \mathrm{~b}$ & $0,12 \mathrm{~b}$ & $0,13 \mathrm{~b}$ & $0,13 \mathrm{~b}$ \\
UCE & $0,14 \mathrm{~b}$ & $0,13 \mathrm{~b}$ & $0,13 \mathrm{~b}$ & $0,12 \mathrm{~b}$ \\
UCV & $0,13 \mathrm{~b}$ & $0,13 \mathrm{~b}$ & $0,12 \mathrm{~b}$ & $0,13 \mathrm{~b}$
\end{tabular}


*médias seguidas pela mesma letras na coluna não diferem estatisticamente entre si, pelo teste de Tukey ao nivél de 5\% de probabilidade. Sendo UCT: Uva com cobertura viva do solo em topo; UCE: Uva com cobertura viva do solo em encosta; UCV: Uva com cobertura viva do solo em Várzea e MN: Mata Nativa.

Na Tabela 2 pode-se verificar na que não houve diferenças significativas entre as médias de umidade gravimétrica entre o manejo em topossequência. $\mathrm{O}$ que pode ser evidenciado que solos sob cultivo, que vem a ser corroborado com a Tabela 1, onde verifica-se o aumento da densidade do solo em profundidade, reduzindo dessa forma, a macroporosidade, com consequente perda de sua capacidade natural de armazenamento de água e consequentemente de possuíram menores valores de umidade. Ainda conforme Guariz et al. (2009) os menores valores de umidade provocam menores valores de densidade do solo como também foi observado neste trabalho (Tabela 1), principalmente no momento da coleta do anel. Solos mais secos, geralmente necessitam de maior número de impactos para que o anel penetre no perfil do solo.

A mata diferiu estatisticamente dos demais tratamentos com um elevado teor de umidade gravimétrica em todas as camadas avaliadas. Tais resultados comprovam o efeito da manutenção de material orgânico oriundo de restos animais e vegetais oriundos de vegetação nativa não alterada contribuindo para o aumento da matéria orgânica e consequentemente na retenção de água nas camadas do perfil do solo.

Segundo Souza et al., (2005) a baixa umidade presente no solo tende a sofrer redução nos valores de densidade em função da perda de sua estruturação. A relação entre a densidade do solo e a umidade gravimétrica na área de Mata Nativa, onde ocorreu um comportamento inverso em que os valores de densidade do solo foram menores e os valores de UG maiores, mostrando que quanto maior a umidade de um solo menor será sua densidade. Indicando que o revolvimento do solo pode favorecer a exposição do solo a maior ação de fatores externos que promovem a perda de umidade do solo. 
Figura 2. Valores médios de umidade gravimétrica do solo em ARGISSOLO VERMELHO-AMARELO sob cultivo da Uva Isabel e Mata Nativa. Sendo UCT: Uva com cobertura viva do solo em topo; UCE: Uva com cobertura viva do solo em encosta; UCV: Uva com cobertura viva do solo em Várzea e MN: Mata Nativa.

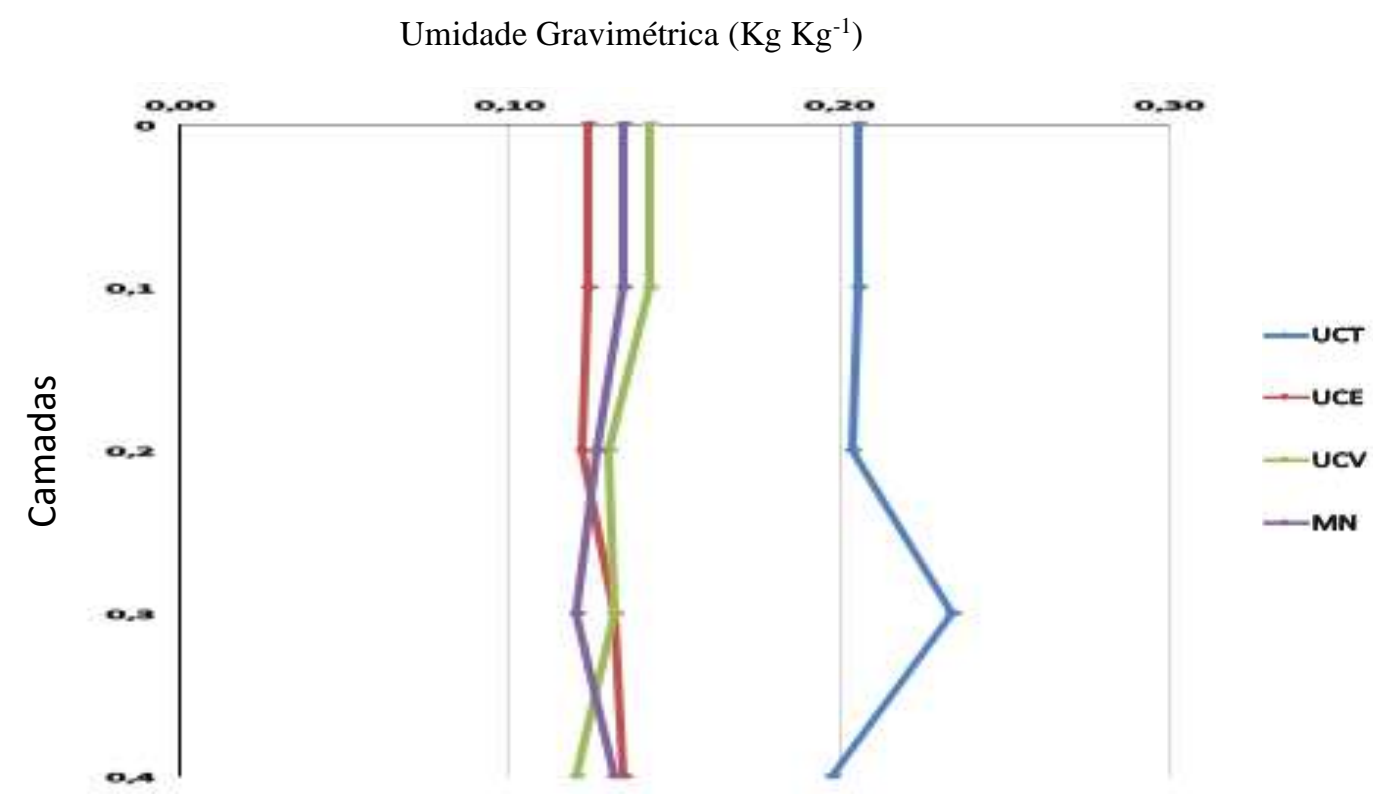

De acordo com a Figura 2, observa-se que a Mata Nativa se destaca em relação aos outros sistemas de uso e manejo da cultura da uva em topossequência, principalmente na profundidade de $0,3 \mathrm{~m}$, e pela distância que sua curva se apresenta de todas as outras curvas. $\mathrm{O}$ que também corrobora com o trabalho de Fernandes, et al., (2014) que verificou o mesmo comportamento da Umidade gravimétrica comparando os atributos físicos de solo sob cerrado em diferentes sistemas de uso e manejo de pastagens e mata nativa Diferentemente do que foi observado no trabalho de Cardoso et al. (2010) onde a umidade gravimétrica nas pastagens não apresentou diferença significativa das áreas de Cerrado (mata nativa).

Em relação aos outros sistemas de uso e manejo da cultura da uva em topossequência a UCE se destaca (Figura 3), pois apresenta homogeneidade de umidade em seu perfil, além de seus valores serem um pouco superiores aos demais. Provavelmente, na UCE sempre haver a cobertura no solo, visto que a roçagem que é dada não provoca o corte excessivo das ervas que se desenvolvem no local, devido a dificuldade na efetivação dessa prática, havendo um período de curto de tempo no qual estas descansam e crescem novamente. 


\section{Conclusões}

1. A alteração da mata nativa em área de cultivo de Uva, seja em qualquer declividade, promove degradação da qualidade física do solo, visto que não há nas áreas de cultivo o manejo correto, tornando esta condição degradadora de solos;

2. O manejo adotado superficialmente com uso de cobertura viva em uva no solo favorece a quebra da camada superficial do solo, garante a redução dos valores de densidade do solo nesta camada, entretanto não reduz a densidade em sub superfície promovendo o aumento dessa propriedade.

3. A densidade do solo e inversamente proporcional a umidade gravimétrica do solo.

\section{Referências}

ALVES, A.J.O. \& RIBEIRO, M.R. Caracterização e gênese dos solos de uma topossequência na microrregião da Mata de Pernambuco. R. Bras. Ci. Solo, 19:297-305, 1995.

AMARO FILHO, J.; NEGREIROS, R.F.D.; ASSIS JÚNIOR, R.N.\& MOTA, J.C.A. Amostragem e variabilidade espacial de atributos físicos de um Latossolo Vermelho em Mossoró, RN. R. Bras. Ci. Solo, 31:415-422, 2007.

BERTOL, I.; ALBUQUERQUE, J. A.; LEITE, D.; AMARAL, A. J. e ZOLDAN JR, W. A. Propriedades físicas do solo sob preparo convencional e semeadura direta em rotação e sucessão de culturas, comparadas as do campo nativo. Revista Brasileira de Ciência do Solo, v.28, p.155-163, 2004.

BOTTEGA, E.L.; BOTTEGA, S.P.; SILVA, S.A.; QUEIROZ, D.M.; SOUZA, C.M.A.; RAFULL, L.Z.L. Variabilidade espacial da resistência do solo à penetração em um Latossolo Vermelho distroférrico. R. Bras. Ci. Agrárias, 6:331-336, 2011.

CAMARGO, L.A.; MARQUES JÚNIOR, J.; PEREIRA, G.T. \& HORVAT, R.A. Variabilidade espacial de atributos mineralógicos de um Latossolo sob diferentes formas do relevo. II Correlação espacial entre mineralogia e agregados. R. Bras. Ci. Solo, 32:2279-2288, 2008.

CANTÓN, Y.; SOLÉ-BENET, A.; LÁZARO, R. Soilgeomorphology relations in gypsiferous materials of the Tabernas Desert (Almería, SE Spain). Geoderma, Amsterdam, v. 115, n. 2, p. 193-222, 2003.

CARDOSO, E. L.; SILVA, M. L. N.; FREITAS, D. A. F. de. Resistência do Solo à Penetração Sob Vegetação Nativa e Pastagem Cultivada no Pantanal Sul-Mato-Grossense. In: SIMPAN, 5, 2010, Corumbá-MS. Anais... Corumbá-MS, 2010, p. 1-4. 
CARDOSO, J.A.F. Atributos químicos e físicos do solo e matéria orgânica do solo sob mangueira irrigada e caatinga nativa na região do Vale do Submédio São Francisco. 2014. $78 f$ (Dissertação) - Universidade Federal do Vale do São Francisco, UNIVASSF, Juazeiro/BA, 2014.

COBERTURA DO SOLO. Disponivel em http://ambientes.ambientebrasil.com.br/agropecuario/erosao_do_solo/cobertura_do_solo.html. Acessado em 10 de Outubro de 2018.

CUSTÓDIO, G. D.; RIBON, A. A.; FERNANDES, K. L.; et al. Densidade do solo e densidade relativa - indicadores da qualidade física de um Latossolo Amarelo sob diferentes manejos de pastagens e mata nativa. Campo Digital, v.10, n.1, p.50-62, 2015.

EMBRAPA, TAVARES, S. C. C. de H. e LIMA, V. C. A indicação geográfica da uva de São Vicente Férrer e Macaparana - PE a partir de pesquisas da Embrapa. Circular técnica 43, Rio de Janeiro - RJ, 2009.

Embrapa Semiárido. 2009. LEÃO, P.C. de S. e BORGES, R. M. E. Melhoramento genético da videira. Petrolina: 61p. [Embrapa Semi-árido. Série Documentos,224].

Embrapa Uva e Vinho. 2010. CAMARGO, U.C ; MAIA, J.D.G e RITSCHEL, P. Novas cultivares Brasileiras de uva. Bento Gonçalves- RS;66 p. 2010.

FERNANDES, K. L.; RIBON, A. A.; Hermógenes, V. T. L.; CUSTÓDIO, G. D. BARROS, L. $R$. Atributos físicos do solo sob cerrado em diferentes sistemas de uso e manejo de pastagens e mata nativa. Cultivando o saber, V. 7, n.1, p. 14-23, 2014.

FERREIRA, R. R. M.; TAVARES FILHO, J.; FERREIRA, V. M. Efeitos de Sistemas de Manejo de Pastagens nas Propriedades Físicas do Solo. Semina: Ciências Agrárias, Londrina, v. 31, n. 4, p. 913-932, out./dez. 2010.

FIGUEIREDO, C. C.; RAMOS, M. L. G.; TOSTES, R. Propriedades físicas e matéria orgânica de um LATOSSOLO VERMELHO sob sistemas de manejo e cerrado nativo. Bioscience Jornal, Uberlândia, v.24, n.3, p.24-30, jul./set. 2008.

FLORES, C. A. et al. Vinhos de Pinto Bandeira: características de identidade regional para uma indicação geográfica. Bento Gonçalves: Embrapa Uva e Vinhos, 2005, 11p. (Embrapa Uva e Vinho. Circular Técnica, 55).

GUARIZ, H. R. et al. Variação da umidade e da densidade do solo sob diferentes coberturas vegetais. Anais do XIV Simpósio Brasileiro de Sensoriamento Remoto, Natal, Brasil, 2530 abril de 2009, INPE, p. 7709-7716.

IMHOFF, S.; SILVA, A. P. da; TORMENA, C. A. Aplicações da Curva de Resistencia no Controle da Qualidade Física de um Solo sob Pastagem. Pesquisa Agropecuária Brasileira, Brasília, v. 35, n. 7, p. 1493-1500, jul. 2000.

KIEHL, E. J. Manual de Edafologia. 1.ed. São Paulo: Agronômica Ceres, 1979. 262p. 
MELLO, L. M. R. de. Desempenho da vitivinicultura brasileira em 2015. EMBRAPA. Disponível em: <https://www.embrapa.br/busca-de-noticias/-/noticia/9952204/artigodesempenho-da-vitivinicultura-brasileira-em-2015. Acessado em 20 de Novembro de 2018.

PHILLIPS, D. H. et al. Soil-landscape relationships at the lower reaches of a watershed at Bear Creek near Oak Ridge, Tennessee. Catena, Amsterdam, v. 44, n. 3, p. 205- 222, 2001.

PREVEDELLO, J.; REINERT, D. J.; REICHERT, J. M.; BRAGA, F. V. A.; GUBIANI, P. I.; CORCINI, A. L. M. Efeito do manejo do solo nas propriedades físicas e no desenvolvimento inicial de Eucalyptus grandis. In: CONGRESSO BRASILEIRO DE CIÊNCIA DO SOLO, 31. 2007, Gramado-RS. Anais... Gramado-RS, 2007. 5p.

Raij, B. V. Fertilidade do solo e manejo de nutrientes. Internacional Plant Nutrion Institute, 2011.

REINERT, D. J.; REICHERT, R. M. Propriedades físicas do solo. Santa Maria, UFSM, 18 p., 2006.

SÃO VICENTE FERRER. $\quad$ Disponível em: https://pt.wikipedia.org/wiki/S\%C3\%A3o_Vicente_F\%C3\%A9rrer_(Pernambuco)>. Acessado em 18 de Julho de 2018.

SILVA, V.R.; REICHERT, J.M. \& REINERT, D.J. Variabilidade espacial da resistência do solo à penetração em plantio direto. Ci. Rural, 34:399-406, 2004.

SOUZA, Z.M.; CAMPOS, M.C.C.; CAVALCANTE, Í.H.L.; MARQUES JÚNIOR, J.; CESARIN, L.G. \& SOUZA, S.R. Dependência espacial da resistência do solo à penetração e teor de água do solo sob cultivo de cana-de-açúcar. Ci. Rural, 36:128-134, 2006.

SOUZA, J. S. I. de. Uvas para o Brasil. 2. ed. rev. aum. Piracicaba: FEALQ, 1996. 791 p.

SOUZA, D.M.G.; MIRANDA, L.N.; OLIVEIRA, S.A. Acidez do solo e sua correção. In: NOVAIS, R.F.; ALVAREZ, V., V.H.; BARROS, N.F.; FONTES, R.L.F.; CANTARUTTI, R.B.; NEVES, J.C.L. Fertilidade do solo. Viçosa, MG, Soci. Bras. Ci. do Solo, 2007. 991p.

SOUZA, E. D.; CARNEIRO, M. A. C.; PAULINO, H. B. Atributos físicos de um Neossolo Quartzênico e um Latossolo Vermelho sob diferentes sistemas de manejo. Pesquisa Agropecuária Brasileira, v.40, n.11, 2005. SOUZA, E. D.; CARNEIRO, M. A. C.; PAULINO, H. B. Atributos físicos de um Neossolo Quartzênico e um Latossolo Vermelho sob diferentes sistemas de manejo. Pesquisa Agropecuária Brasileira, v.40, n.11, 2005.

TOPOSSEQUÊNCIA. 